\title{
INVERSION OF BOTTOM HOLE TEMPERATURES FOR GRADIENT DETERMINATION BY THE DAMPED LEAST SQUARES METHOD FOR NOISE ATTENUATION
}

\author{
Artur Santos Benevides ${ }^{1}$ and Amin Bassrei²
}

\begin{abstract}
This study consists in obtain the 1-D distribution of the geothermal gradient from the inversion of Bottom Hole Temperature (BHT) data. Before the inversion procedure, Horner correction method was used to determine the correct formation temperature. The inversion was performed in a synthetic model based on real data from Pineview Field (Utah, USA), in this case, to obtain geothermal gradients from nine formations using BHT data from 32 wells. The $Z$ matrix of the geothermal problem contains the elements $z_{i j}$, i.e., the thickness of the $i$-th layer logged in the $j$-th well. The least squares method was used, and, because of the occurrence of noise, damping was required. The numerical implementation of the inversion, i.e., the determination of the inverse operator $\left(Z^{T} Z\right)^{+}$or $\left(Z^{T} Z+\varepsilon^{2} I\right)^{+}$was performed by singular value decomposition. Initial inversions did not produce satisfactory results, but they significantly improved with the introduction of damping. The improvement of the results is quantitatively explained by the fact that the condition number of the matrix to be inverted greatly reduced with the use of the damping. In turn, damping requires the choice of an optimal parameter, and the L-curve was used for this purpose.
\end{abstract}

Keywords: inverse problems; geothermal gradient, bottom hole temperature.

RESUMO. Neste trabalho foram utilizados dados BHT - Bottom Hole Temperature ou temperatura de fundo de poço na inversão de dados com o objetivo de obter a distribuição 1-D do gradiente geotérmico. Antes da inversão propriamente dita, foi utilizado o método de correção de Horner, para determinar a temperatura correta da formação. A inversão foi realizada em um modelo sintético inspirado em dados reais do Campo de Pineview (Utah, EUA), no caso, com o objetivo de obter gradientes geotérmicos de nove formações utilizando dados BHT de 32 poços. A matriz $Z$ do problema geotérmico contém os elementos $z_{i j}$, ou seja, a espessura da $i$-ésima camada perfilada no j-ésimo poço. 0 método dos mínimos quadrados foi utilizado, e devido à existência de ruído foi necessário 0 amortecimento. A implementação numérica da inversão, ou seja, a determinação do operador inverso $\left(Z^{T} Z\right)^{+}$ou $\left(Z^{T} Z+\varepsilon^{2} I\right)^{+}$foi através da decomposição em valores singulares. As inversões iniciais não geraram resultados satisfatórios, melhorando bastante com a introdução do amortecimento. A melhoria dos resultados é explicada quantitativamente pelo fato do número de condição da matriz a ser inversa reduziu bastante com a utilização do amortecimento. Por seu turno, 0 amortecimento demanda a escolha de um parâmetro ótimo, sendo que foi utilizada a curva $L$ para esse fim.

Palavras-chave: problemas inversos; gradiente geotérmico, temperatura de fundo de poço.

Corresponding author: Amin Bassrei

1 Observatório Nacional, R. Gen. José Cristino, 77, São Cristóvão 20921-400 Rio de Janeiro, RJ, Brazil - E-mail: benevidesartur@gmail.com

2 Universidade Federal da Bahia, CPGG/IGEO/UFBA; INCT-GP, Rua Barão de Jeremoabo, s/n, Ondina 40170-115, Salvador, BA, Brazil - E-mail: bassrei@ufba.br 


\section{INTRODUCTION}

Many theories or hypotheses created to explain the geological events that occur depend on terrestrial heat, which provides the energy required for overlays, faults, inelastic deformations, and the movements of magma and water (Fowler, 2005). Geothermal heat is one of the required elements for hydrocarbon maturation in sedimentary basins. In the last decades several studies of sedimentary basins were carried out by analysis of measured temperature, geothermal gradient and geothermal flow calculations (Fontes, 1980).

Bottom Hole Temperature (BHT) measurement is part of the geophysical well logging practice and is measured in a short period after the well drilling is performed at each well stage (Chapman et al., 1984). During drilling, a thermal field disturbance occurs in the adjacent formations, caused mainly by two factors. The first cause is the release of heat by the drill during drilling, resulting in heating in the formations adjacent to the well, especially in regions closer to the surface. The second cause is the circulation of the drilling mud, which assists in the lubrication of the drill bit and the transport of the crushed material. The mud moves down to the drilling point and then rises to the surface. This convection movement removes the heat from deeper regions and brings it to the surface. To obtain good quality data, it is necessary to correct the BHT measurements. Thus, this study applied the Horner method, which uses two measurements collected at the same depth at different times to determine the equilibrium temperature.

This study aimed to determine the geothermal gradient $g$ of the various formations along a profile. In addition to the BHT data, surface temperature measurements and thicknesses of the subsurface formations were also used. The geothermal gradient is considered to vary only in the direction of the $z$ axis, which is the depth. The average $g$ of a stack of sedimentary layers is equal to the ratio between the temperature variation (well bottom to the surface) and the depth, which is the distance $z$ between measurement points. An average gradient is then calculated for a well and its surrounding region. This procedure is carried out because of the lack of temperature information, which is due to non-continuous measurement during well logging, unlike other conventional geophysical well logs, where measurement is performed every $0.5 \mathrm{ft}$ or approximately $15 \mathrm{~cm}$.

Because of this limitation in the measurement process, we used the data inversion methodology, a technique to estimate the model parameters, which in this application is the 1-D distribution geothermal gradient written as the vector $g$. The input data of the problem are the temperature differences between the well bottom and the surface. The thicknesses of the layers form the matrix $Z$, whose inverse must be calculated to determine the model parameters. Since the matrix $Z$ is generally singular, the classical inverse cannot be calculated, but rather the generalized inverse $Z^{+}$(Penrose, 1955), using singular value decomposition or SVD (Lanczos, 1961). In addition to the inversion of the matrix $Z$, the least squares method usually applied to overdetermined systems, was also used, as well as an extension of it, the damped least squares method, which aims to compensate the singularity of the matrix $Z^{T} Z$. In the latter method, there is the need to choose the damping parameter, and the appropriate choice will provide a solution with both physical feasibility and reasonable accuracy.

The inversion was performed in a synthetic model based on real data from Pineview Field (Utah, USA). The model has nine different formations, each one with a specific gradient and 32 BHT data. The inversions using least squares method did not bring good results, but the quality of the solutions improved significantly with damping, which was proven by the reduction of the RMS error between the true model and the estimated solution. As previously mentioned, damping requires the choice of an optimal parameter, which was derived from the L-curve, where the abscissas correspond to the norm of the error vector between the observed and calculated data, $\|e\|=\left\|Z g^{e s t}-\Delta T^{o b s}\right\|$, and the ordinates correspond to the solution norm $\left\|g^{\text {est }}\right\|$. When displayed on a log-log scale, this curve usually resembles the shape of the letter $L$, where the inflection region represents the region of interest because it indicates the best regularization parameter. In this case, $\varepsilon^{2}=10^{4}$ was chosen for the three noise levels.

\section{BOTTOM HOLE TEMPERATURE AND CORRECTIONS}

After the well drilling, the well logging process starts, before the well casing. At the well bottom, there is an accumulation of the drilling mud that is supposed to be in thermal equilibrium with the formations neighboring the well walls. At this point, the BHT measurement is performed as shown in Figure 1, with more than one measurement in the same well and at the same depth. The BHT measurements mostly do not correspond to the true formation temperatures, since during drilling the well bottom temperature is disturbed by the drilling tool and by the variation of the drilling fluid itself (Bullard, 1947). 


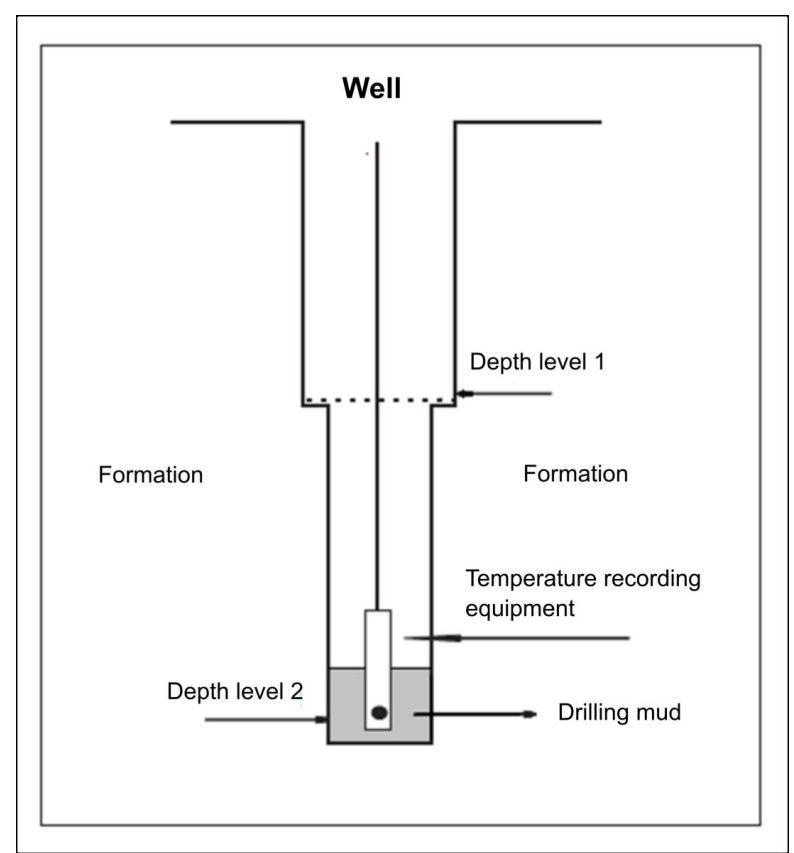

Figure 1-Diagram showing the bottom hole temperature measurement. Adapted from Cavalcante (2004).

The thermal perturbations caused by the drilling activity occur because of two processes that act in opposite directions (Cardoso, 2007): (i) heating, mainly in the regions closer to the surface, because of the great heat release generated by the friction of the drill bit with the rock formation being drilled; (ii) cooling, more evident in deeper regions, because of the fact that the injected fluid is usually at lower temperatures than those of the geological formations in depth and acts as a convection process, taking the heat from the deeper regions to the surface of the earth, which has lower temperature.

Figure 2 shows a diagram of the temperature evolution with depth, in which a rise temperature is observed at relatively small depths (around hundreds of meters), where the effect of heating is greater than the cooling process because of the process of the drill bit. At higher depths, the effect of cooling is greater than that of heating, and thus the temperature reduces. These two sources of heat exchange tend to generate two distinct zones of thermal disturbance within the well.

The BHT data correction methodologies can be divided into two classes. The first one aims to simulate the temperature evolution in the well using the drilling history, requiring data such as the composition of the drilling mud, the mud temperature in the injection, the circulation rate of the fluid, physical properties of rocks, among others. The second class aims to determine the true temperature by mathematical modeling.
The correction method described as the first class becomes infeasible most of the time, because we do not have enough information, which leads us to require to mathematical models, which in turn would have two subclasses: (i) mathematical modeling and (ii) empirical methods. Mathematical modeling generally relies on physical laws that can relate well geometry, heat sources involved, and physical properties of rocks, among others. The empirical methods generally assign a correction factor obtained by the analysis of the BHT and STF measurements (static temperature of the formation), to which, most of the time, a correction is made considering the depth of the measurements. These methods are mostly calibrated for a given region.

In this study, we used a mathematical method called Horner correction. Among the researches that used this method, we can mention Fontes (1980), Luheshi (1983), Chapman et al. (1984), Deming \& Chapman (1988), and Cavalcante (2004). The Horner method was adapted for the borehole temperature problem by Lachenbruch \& Brewer (1959) and it uses the thermal recovery model in a well after periods of disturbance by mud circulation proposed by Bullard (1947):

$$
T_{\infty}=T\left(t_{s}\right)+\frac{Q^{\prime}}{4 \pi K}\left[\ln \left(\frac{t_{s}}{t_{s}+t_{c}}\right)\right]
$$

where $T\left(t_{s}\right)$ is the BHT at a given moment after cessation of mud circulation, $T_{\infty}$ represents the assumed STF, $t_{c}$ is the mud circulation period, $t_{s}$ is the rest time of the of mud on well (between the end of the mud circulation and the BHT measurement), $Q^{\prime}$ represents the energy of the linear heat source emanating from the center of the well, and $K$ is the thermal conductivity of the mud formation system.

We can obtain STF by the Horner method by plotting for each data set measured at the same depth a straight line that best fits the points of $T_{\infty} \times \ln \left(t_{s} / t_{s}+t_{c}\right)$, in which we need to obtain $T_{\infty}$, which will be the STF when the difference between the exponential integrals $\ln \left(t_{s} / t_{s}+t_{c}\right)$ is zero. For this to occur, $t_{s}$ must tend to infinity. Adjusting Eq. (1) by least squares method, the value of $T_{\infty}$ is obtained by extrapolating the adjusted straight line.

\section{INVERSE PROBLEMS AND SINGULAR VALUE DECOMPOSITION}

The inversion aims to determine parameters from observed data, or, because of the inevitable limitations in the actual measurement processes, the maximum possible information about such parameters. The direct problem can be represented as: 


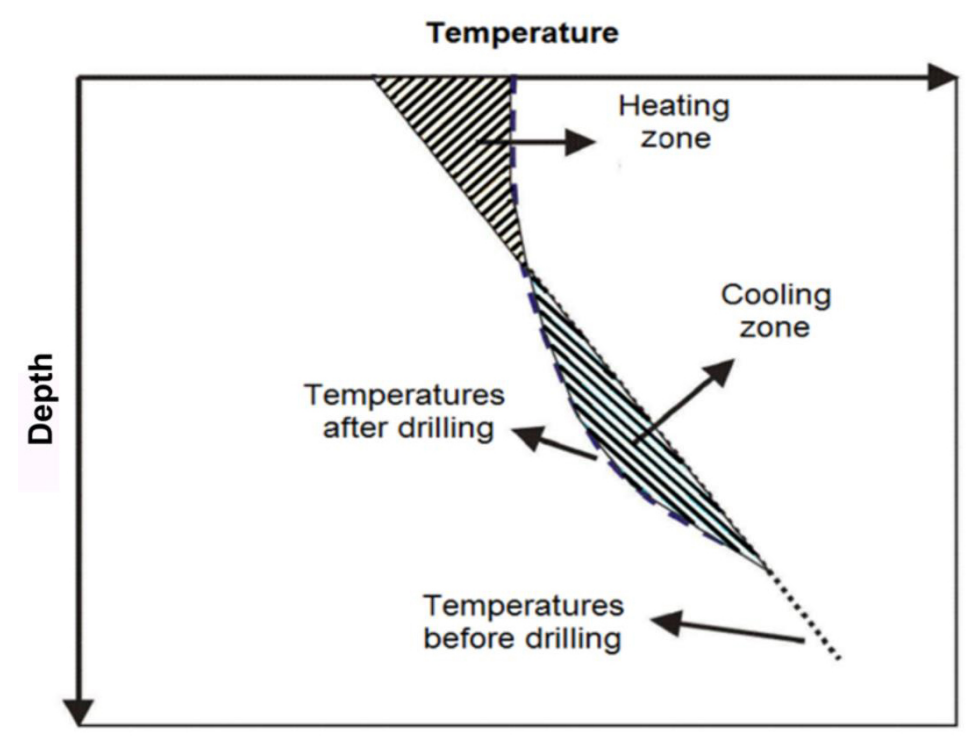

Figure 2 - Schematic representation of the effect of perturbations on temperatures caused by drilling activity. Adapted from Cardoso (2007).

$$
\Delta T=Z g
$$

where $\Delta T=\left[\Delta T_{1}, \Delta T_{2}, \ldots, \Delta T_{M}\right]^{T}$ is the vector of observed data, in this case the temperature differences between the well bottom and the surface, and $g=\left[g_{1}, g_{2}, \ldots, g_{N}\right]^{T}$ is the vector of model parameters that are the geothermal gradients of subsurface layers. $Z$ is an $M \times N$ matrix that relates the $M$ observed data to the $N$ model parameters, and is expressed as:

$$
Z=\left[\begin{array}{ccccc}
z_{11} & z_{12} & z_{13} & z_{14} & z_{1 N} \\
z_{21} & z_{22} & z_{23} & z_{24} & z_{2 N} \\
\vdots & \vdots & \vdots & \ddots & \vdots \\
z_{M 1} & z_{M 2} & z_{M 3} & \ldots & z_{M N}
\end{array}\right]
$$

One can solve the system so that:

$$
g^{e s t}=Z^{+} \Delta T^{o b s},
$$

where $Z^{+}$is the pseudo-inverse matrix. For the case in which the system has more equations than unknowns, i.e., an overdetermined system, the least squares method is used, obtaining the solution that minimizes the square of the error, whose solution is:

$$
g^{e s t}=\left(Z^{T} Z\right)^{+} Z^{T} \Delta T^{o b s}
$$

An extension of the least squares method, called damped least squares method, proposed by Levenberg (1944) and Marquardt (1963), allows one to obtain a solution when the matrix is singular, with addition of a non-negative parameter $\varepsilon^{2}$ in the main diagonal of $Z^{T} Z$ :

$$
g^{\text {est }}=\left(Z^{T} Z+\varepsilon^{2} I\right)^{+} Z^{T} \Delta T^{o b s}
$$

The choice of factor $\varepsilon^{2}$ should maintain a compromise between a small value that does not compromise the solution and a value large enough to amend the poor conditioning of the system.

In the analysis of the inversion results, one must calculate the errors involved. The relative RMS (Root Mean Square) error between the true and estimated model is expressed as:

$$
e_{R M S, g}=\frac{\sqrt{\sum_{i=1}^{N}\left(g_{i}^{\text {true }}-g_{i}^{\text {est }}\right)^{2}}}{\sqrt{\sum_{i=1}^{N}\left(g_{i}^{\text {true }}\right)^{2}}} \times 100 \%,
$$

while the error between the observed and calculated data $\left(\Delta T^{\text {cal }}=Z g^{\text {est }}\right)$ is given by:

$$
e_{R M S, \Delta T}=\frac{\sqrt{\sum_{i=1}^{M}\left(\Delta T_{i}^{o b s}-\Delta T_{i}^{c a l}\right)^{2}}}{\sqrt{\sum_{i=1}^{M}\left(\Delta T_{i}^{o b s}\right)^{2}}} \times 100 \% .
$$

In this study the pseudo-inverse is calculated by singular value decomposition or SVD (Lanczos, 1961). Let $Z$ be a real $M \times N$ matrix. The $Z^{+}$with dimensions $N \times M$ will be its unique 
pseudo-inverse, if the following conditions are satisfied (Penrose, 1955): (i) $Z Z^{+} Z=Z$, (ii) $Z^{+} Z Z^{+}=Z^{+}$, (iii) $\left(Z Z^{+}\right)^{T}=$ $Z Z^{+}$, and (iv) $\left(Z^{+} Z\right)^{T}=Z^{+} Z$. Assuming a rectangular matrix $Z_{M \times N}$ with rank $k$, its decomposition is obtained from the formula $Z=U \Sigma V^{T}$, where $U_{M \times M}$ is the matrix containing the orthonormalized eigenvectors of $Z Z^{T}, \Sigma_{M \times N}$ is the matrix containing the singular values of $Z$, and $V_{N \times N}$ is the matrix containing the orthonormalized eigenvectors of $Z^{T} Z$. Then, the pseudo-inverse, or inverse generalized, is the $N \times M$ matrix $Z^{+}=V \Sigma^{+} U^{T}$, where the $N \times M$ matrix $\Sigma^{+}$contains the reciprocal of the nonzero singular values of $Z$, as follows:

$$
\Sigma^{+}=\left[\begin{array}{cc}
E & 0 \\
0 & 0
\end{array}\right]
$$

where $E$ is the diagonal $k \times k$ matrix whose $i$-th diagonal element is $e_{i i}=\sigma_{i}^{-1}$ for $1 \leq i \leq k$ :

$$
E=\left[\begin{array}{cccc}
\sigma_{1}^{-1} & 0 & \ldots & 0 \\
0 & \sigma_{2}^{-1} & \ldots & 0 \\
\vdots & \vdots & \ddots & \vdots \\
0 & \ldots & 0 & \sigma_{k}^{-1}
\end{array}\right]
$$

\section{BHT DATA INVERSION FOR THE DETERMINATION OF THE GEOTHERMAL GRADIENT}

Consider the hypothetical situation with five wells in a medium with three horizontal layers. Given the measurements of $T$ in a well, the geothermal gradient $g$ can be defined by:

$$
g=\frac{\partial T}{\partial Z}
$$

Eq. (11) gives the average value $g$, which would be the contribution of all the formations present between the surface and the well bottom. The average $g$ value does not consider the different thermal properties inherent to the lithology of each formation, as observed in Figure 3. Given a constant thermal flux, the geothermal gradient is related to the thermal conductivity of the rocks, which is an intrinsic property of the material and that varies significantly along with the lithology of the formations. Thus, a reexamination of Figure 3 indicates that, since there are three different formations, the average geothermal gradient will not be uniform, varying from formation to formation.

Consider that the temperature variation is calculated as

$$
\Delta T=B H T-T_{\text {Sup }}
$$

where $B H T$ is the bottom temperature of the well and $T_{\text {Sup }}$ the surface temperature. Substituting the above expression in Eq. (11), one has $\Delta T / \Delta z=g$ or

$$
\Delta T=\Delta z g
$$

Generalizing Eq. (13) for a set of $M$ wells and $N$ geological layers, we have the following system of linear equations:

$$
\left\{\begin{array}{ccccc}
\Delta T_{1}= & z_{11} g_{1}+ & z_{12} g_{2}+ & \ldots & +z_{1 N} g_{N} \\
\Delta T_{2}= & z_{21} g_{1}+ & z_{22} g_{2}+ & \ldots & +z_{2 N} g_{N} \\
\vdots & : & \vdots & \ddots & \vdots \\
\Delta T_{M}= & z_{M 1} g_{1}+ & z_{M 2} g_{2}+ & \ldots & +z_{M N} g_{N}
\end{array}\right.
$$

which is expressed in vector notation as:

$$
\Delta T=Z g
$$

where $\Delta T$ is the observed data vector that contains the temperature differences between the well bottom and the surface, $g$ represents the vector of model parameters that are the thermal gradient of the formations, and $Z$ is a $M \times N$ matrix containing the thicknesses of the logged formations: $z_{i j}$ is the thickness of the $j$-th logged layer in the $j$-th well. The inversion of Eq. (14) can be obtained from several approaches, according to Eqs. (4), (5) and (6). In the particular case of Eq. (4), the operator $Z^{+}$must be obtained using SVD, so that the solution obtained is $g=Z^{+} \Delta T$.

\section{FIELD-BASED SYNTHETIC DATA FROM PINEVIEW FIELD (UTAH, USA)}

The inverse problem approach for determining the geothermal gradient was employed by Deming \& Chapman (1988) for Pineview Field, using $l_{1}$ and $l_{2}$ norms. Pineview Field (see Fig. 4) is located in the northwestern part of the state of Utah, United States, near the border with the state of Wyoming. The field is part of the Absaroka complex called the Absaroka thrust belt. The field was discovered in 1975, and for several years was a major oil producer. It is contained in a complex geological environment with several structures mostly caused by tectonic efforts. The present faults are of thrust type, mostly with a tendency toward the north-northeast directions, and are due to compressive tectonic movements. The edges of these faults are physically and structurally complex, with numerous folds and secondary faults (Chidsey \& Sprinkel, 2005).

Figure 5 shows a stratigraphic column representative of Pineview Field. The most recent formation, Tw (Wasatch), is 


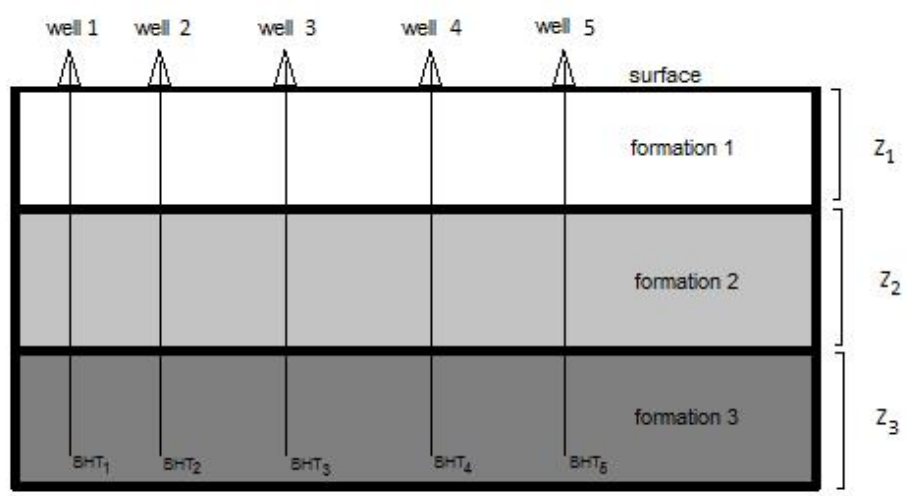

Figure 3 - Section illustrating a geological situation with five wells in three flat layers with different lithologies and geothermal gradients.

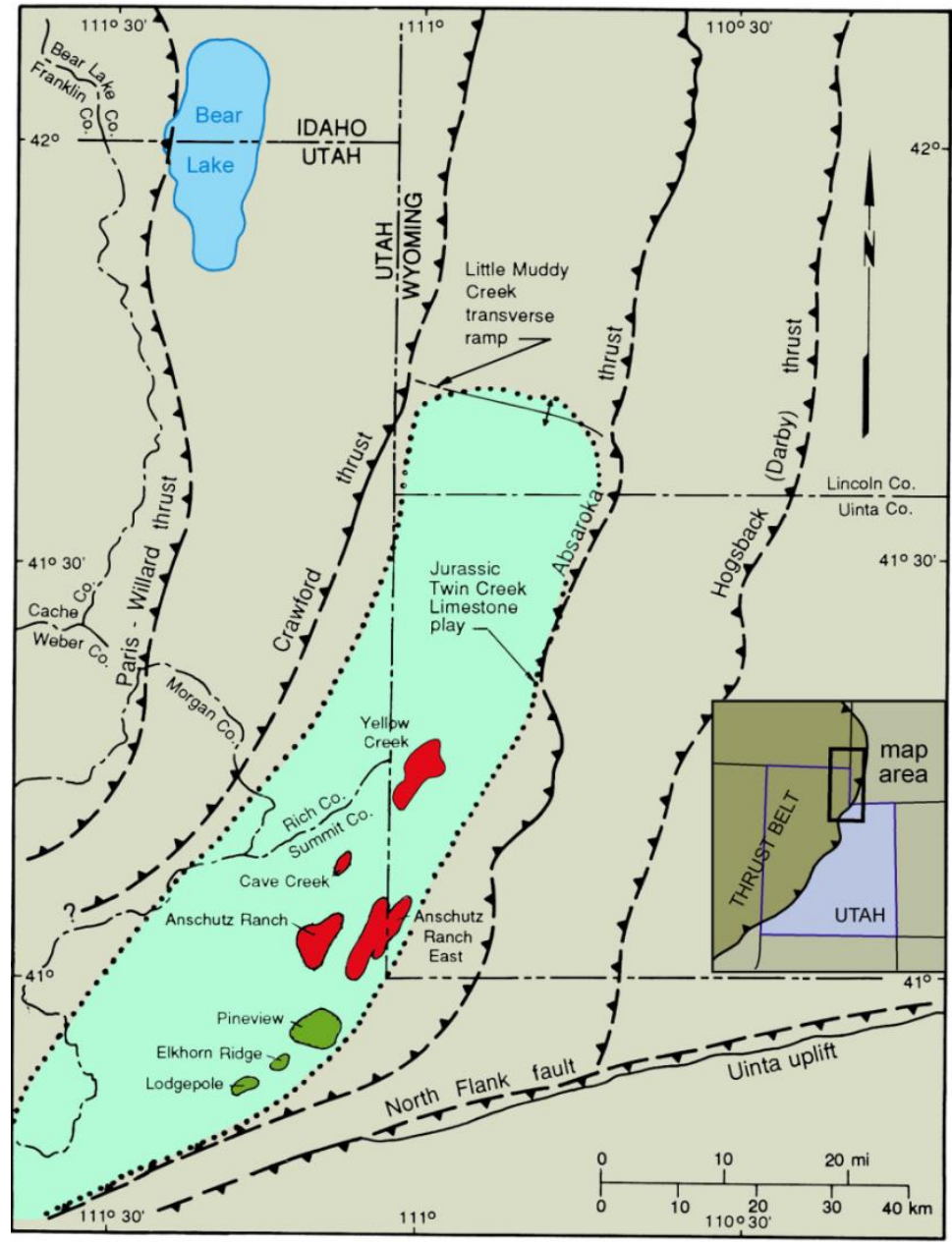

Figure 4 - Pineview Field localization, from Chidsey \& Sprinkel (2005). 
composed of conglomerate; the second formation, $\mathbf{K e c}$, is also composed of conglomerate; $\mathbf{K h}$ (Hilliard) has predominant shale lithology; $\mathbf{K f}$ (Frontier) has a greater predominance of sandstone and secondary participation of shale; Ka (Aspen) is composed of shale and, along with $\mathbf{K f}$, has the smallest representations in the matrix of thicknesses; Kk (Kelvin) has greater representation and is composed of shale; Jsp is the union of the Stump and Preuss members, composed of sandstone, limestone, silt and a layer of salt; the last two formations are Jtc (Twin Creek), with intercalations of limestone and shale, and $\mathbf{J n}$ (Nugget), which is a sandstone reservoir of oil and gas.

Deming \& Chapman (1988) corrected a set with 32 BHT data using the Horner method, which served to determine the thermal gradient of nine formations by the least squares method, which is norm $l_{2}$, and they also used $l_{1}$ norm. They considered the $l_{1}$ norm solution to be the most representative for the Pineview Field data. Thus, this solution was chosen as a reference for our forward modeling. The locations of the wells can be seen in Figure 6 . Based on the gradients determined by the $l_{1}$ norm and the layer thicknesses (see Table 1), Eq. (14) was used to calculate $\Delta T$, which has its values listed in the last column of Table 1 . The $\Delta T$ values form the 32-point vector $\Delta T$, which will be the input data in the inversion algorithm. Note that the average surface temperature was estimated by analyzing the daily and annual variations, and the average value of $T_{S u p}$ adopted for the region was $12^{\circ} \mathrm{C}$ (Eldorado County Weather, 2018).

\section{RESULTS AND DISCUSSION}

For the forward modeling and inversion simulations, the data explained in the previous item and shown in Table 1 were used. With the thicknesses of the layers, the $32 \times 9$ matrix $Z$ was constructed, which characterizes an overdetermined system, i.e., more equations than unknowns. The output of the inverse process are the estimated model parameters $g^{\text {est }}$. Figure 7 shows $g^{\text {est }}$, obtained by the least squares method according to Eq. (5). The various lithologies are presented on the horizontal axis, with no geographical significance. The geothermal gradient is shown on the vertical axis with the unit ${ }^{\circ} \mathrm{C} / \mathrm{km}$. The inversion of matrix $Z^{T} Z$ was obtained by the SVD technique. Note that the estimated solution matches the true model. This is due to the fact that the inverse problem in this case is well-posed, because of the amount of information, and also because the data do not contain noise. However, in real conditions noise always exists, so that to make the simulations realistic, the observed temperature differences were contaminated with Gaussian noise in the following way:

$$
\Delta T_{j}^{o b s}=\Delta T_{j}^{o b s, *}\left(1+\alpha r_{j}\right), j=1, \ldots M,
$$

where $\Delta T_{j}^{o b s}$ is the temperature difference contaminated by noise, $\Delta T_{j}^{o b s, *}$ is the temperature difference uncontaminated by noise, $\alpha$ is the noise factor, and $r_{j}$ is the pseudorandom sequence. In this study three noise levels were tested: $\alpha=0.035, \alpha=0.07$, and $\alpha=0.1$. These noise factors resulted, respectively, in the following relative RMS deviations between the contaminated and uncontaminated data: $R M S_{0.035}=1.04 \%, R M S_{0.07}=2.08 \%$ and $R M S_{0.1}=2.98 \%$. Or roughly to 1,2 , and $3 \%$ of added RMS noise, respectively. The effect of noise impaired the quality of the solution, so that to compensate for this effect, the damped least squares method was used. Thus, instead of inverting the matrix $Z^{T} Z$, we proceeded to the inversion of $\left(Z^{T} Z+\varepsilon^{2} I\right)$, using SVD technique again. Choosing the damping parameter is a problem in itself. The ideal $\varepsilon^{2}$ would be the value that would result in the smallest $e_{R M S, g}$ calculated by Eq. (7). After some tests the range from $10^{0}$ to $10^{5}$ was established for the value of $\varepsilon^{2}$. Out of this range, the results become too inconsistent. Figure 8 shows the curves of the error $e_{R M S, g}$ as a function of $\varepsilon^{2}$ for the three noise levels.

A total of 18 inversions were performed, that is, six inversions for each curve. Each inversion used a different value of $\varepsilon^{2}$. Note that $e_{R M S, g}$ is the minimum for $\varepsilon^{2}=10^{4}$ for all three noise levels. Values of $\varepsilon^{2}$ smaller than $10^{4}$ would characterize an underdamped solution, and for values greater than $\varepsilon^{2}=10^{4}$, the solution would be overdamped. However, the choice of $\varepsilon^{2}$ based on the curve of $e_{R M S, g}$ is suspect, and only possible in a simulation with synthetic data, where the true model $g^{\text {true }}$ is known. In other words, this criterion does not apply to real data. The curves of the data error $e_{R M S, \Delta T}$ were also plotted using Eq. (8), as shown in Figure 9. However, due to the existence of noise and the fact that the inverse problem is essentially ill-posed, the minimum of the $e_{R M S, \Delta T}$ curve does not correspond to the minimum of the $e_{R M S, g}$ curve. In other words, Figure 9 , although didactic, is not useful, since $e_{R M S, \Delta T}$ is minimum for the range of $\varepsilon^{2}$ between $10^{0}$ and $10^{3}$, but the value of $e_{R M S, g}$ in the same range becomes too high with inconsistent results. In summary, it is not surprising that the error criterion is useless and at the same time it is important that the choice of $\varepsilon^{2}$ is not only based on the trial and error criterion.

There are several techniques for choosing the optimal parameter, for example, the L-curve (Hansen, 1992) and the generalized cross validation or GCV (Wahba, 1990). Recent uses of these techniques are presented by Rodrigues \& Bassrei (2016), who used the L-curve in traveltime tomography. GCV was recently used by Mojica \& Bassrei (2015) in inversion of gravity data and 
Table 1 - Set of 32 wells with the thickness (in meters) of each formation and the computed temperature variation (observed data). Data collected from Deming \& Chapman (1988).

\begin{tabular}{|c|c|c|c|c|c|c|c|c|c|c|}
\hline \multirow{2}{*}{ Well } & \multicolumn{9}{|c|}{ Formation and thickness (m) } & \multirow{2}{*}{$\Delta T^{o b s}\left({ }^{\circ} \mathrm{C}\right)$} \\
\hline & Tw & Kec & Kf & Ка & Kk & Jsp & Salt & Jtc & $\mathrm{Jn}$ & \\
\hline $\mathrm{P} 1$ & 0 & 125 & 600 & 175 & 1175 & 405 & 45 & 325 & 200 & 77 \\
\hline P2 & 0 & 90 & 650 & 150 & 1175 & 380 & 45 & 275 & 0 & 69 \\
\hline P3 & 0 & 125 & 625 & 150 & 1200 & 380 & 45 & 0 & 0 & 59 \\
\hline P4 & 0 & 125 & 625 & 175 & 1300 & 455 & 45 & 350 & 300 & 85 \\
\hline P5 & 0 & 125 & 575 & 175 & 1300 & 455 & 45 & 300 & 0 & 75 \\
\hline $\mathrm{P} 6$ & 0 & 150 & 500 & 150 & 1350 & 505 & 45 & 325 & 275 & 82 \\
\hline P7 & 0 & 125 & 550 & 150 & 1250 & 455 & 45 & 200 & 0 & 68 \\
\hline P8 & 0 & 150 & 350 & 150 & 1250 & 480 & 45 & 325 & 325 & 77 \\
\hline P9 & 0 & 150 & 250 & 175 & 1300 & 505 & 45 & 325 & 300 & 76 \\
\hline P10 & 0 & 125 & 50 & 175 & 1500 & 605 & 45 & 350 & 0 & 72 \\
\hline $\mathrm{P} 11$ & 0 & 125 & 0 & 75 & 1525 & 555 & 45 & 325 & 125 & 70 \\
\hline P12 & 0 & 125 & 0 & 0 & 1550 & 455 & 45 & 0 & 0 & 51 \\
\hline P13 & 0 & 175 & 0 & 0 & 1800 & 535 & 45 & 350 & 225 & 79 \\
\hline P14 & 50 & 200 & 0 & 0 & 1425 & 535 & 45 & 350 & 0 & 65 \\
\hline P15 & 150 & 175 & 0 & 0 & 1550 & 635 & 45 & 350 & 275 & 78 \\
\hline P16 & 175 & 150 & 0 & 0 & 1500 & 380 & 45 & 375 & 125 & 69 \\
\hline P17 & 225 & 175 & 0 & 0 & 1575 & 435 & 45 & 375 & 75 & 74 \\
\hline P18 & 250 & 150 & 0 & 0 & 1400 & 405 & 45 & 0 & 0 & 53 \\
\hline P19 & 350 & 200 & 0 & 0 & 1400 & 455 & 45 & 375 & 275 & 77 \\
\hline P20 & 350 & 225 & 0 & 0 & 1200 & 455 & 45 & 0 & 0 & 52 \\
\hline P21 & 375 & 200 & 0 & 0 & 1150 & 435 & 45 & 250 & 0 & 60 \\
\hline P22 & 400 & 225 & 0 & 0 & 1075 & 455 & 45 & 325 & 225 & 67 \\
\hline P23 & 500 & 350 & 0 & 0 & 1775 & 305 & 45 & 350 & 300 & 91 \\
\hline P24 & 500 & 325 & 0 & 0 & 1050 & 180 & 45 & 325 & 0 & 61 \\
\hline P25 & 575 & 350 & 0 & 0 & 1150 & 205 & 45 & 350 & 375 & 76 \\
\hline P26 & 600 & 375 & 0 & 0 & 1200 & 135 & 45 & 350 & 375 & 78 \\
\hline P27 & 600 & 325 & 0 & 0 & 1050 & 180 & 45 & 325 & 350 & 65 \\
\hline P28 & 750 & 350 & 0 & 0 & 925 & 305 & 45 & 225 & 0 & 62 \\
\hline P29 & 725 & 350 & 0 & 0 & 775 & 380 & 45 & 275 & 0 & 60 \\
\hline P30 & 775 & 325 & 0 & 0 & 675 & 535 & 45 & 375 & 100 & 67 \\
\hline P31 & 700 & 325 & 0 & 0 & 725 & 780 & 45 & 425 & 175 & 74 \\
\hline P32 & 625 & 325 & 0 & 0 & 675 & 1035 & 45 & 200 & 0 & 62 \\
\hline
\end{tabular}




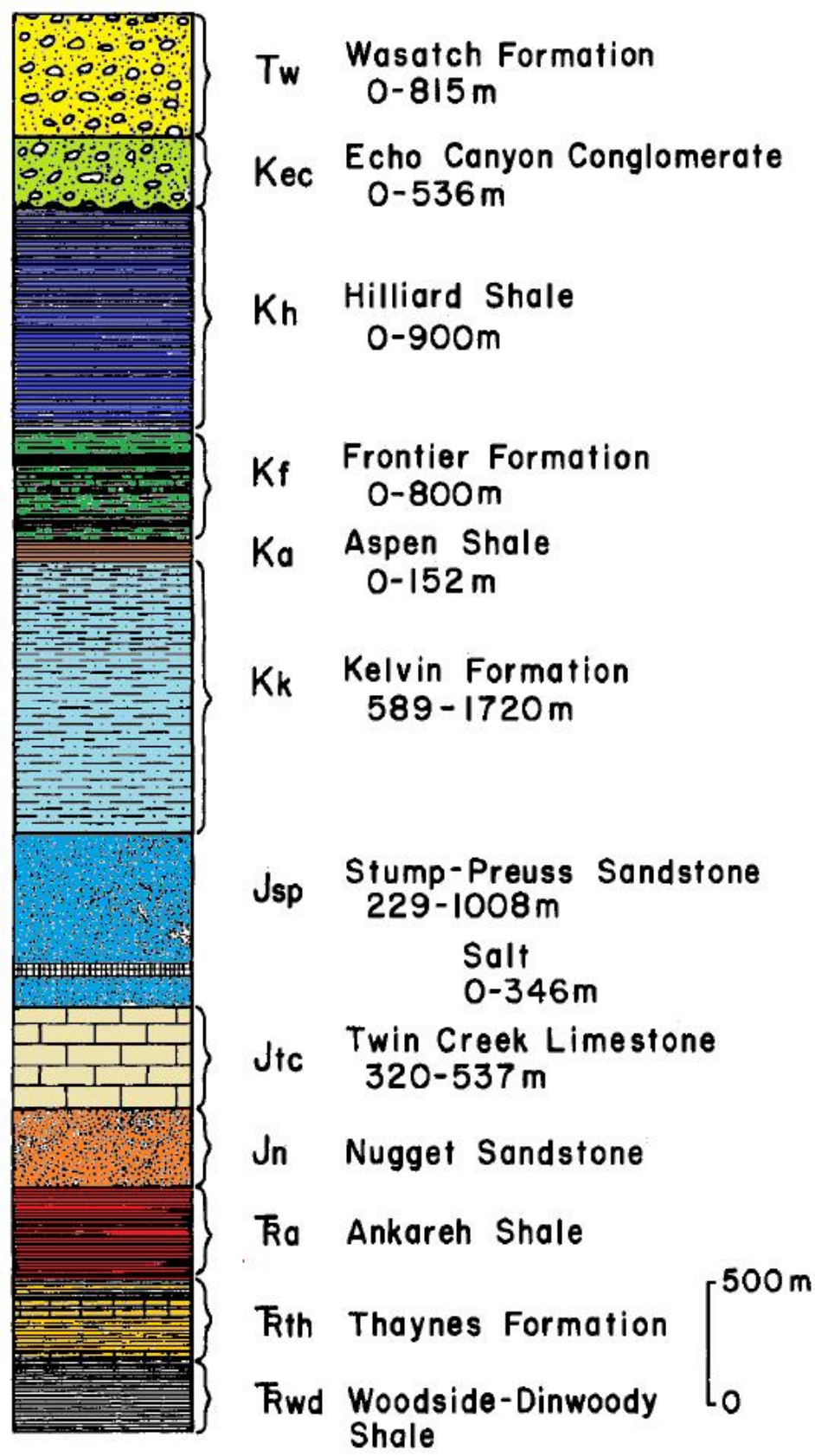

Figure 5 - Pineview Field stratigraphic column, adapted from Deming \& Chapman (1988).

by Silva \& Bassrei (2016) in waveform seismic inversion. In this study we used the L-curve, which is so called because it often has the format of that letter of the alphabet. It is a parametric curve, where each point is associated with a parameter $\varepsilon^{2}$. The horizontal axis represents the inversion error, i.e., the modulus of the difference between the observed data and the calculated data, and the vertical axis represents the energy of the model, which is simply the module of the estimated model. The L-curve has found application in a variety of inverse problems, including in Geophysics, as previously mentioned. However, the visualization of the knee and the consequent extraction of the optimal parameter are not always trivial tasks, especially when the L-curve does not have the letter $L$ shape. Six values for $\varepsilon^{2}$ were used, in the same range from $10^{0}$ to $10^{5}$. Figure 10 shows the L-curve for 


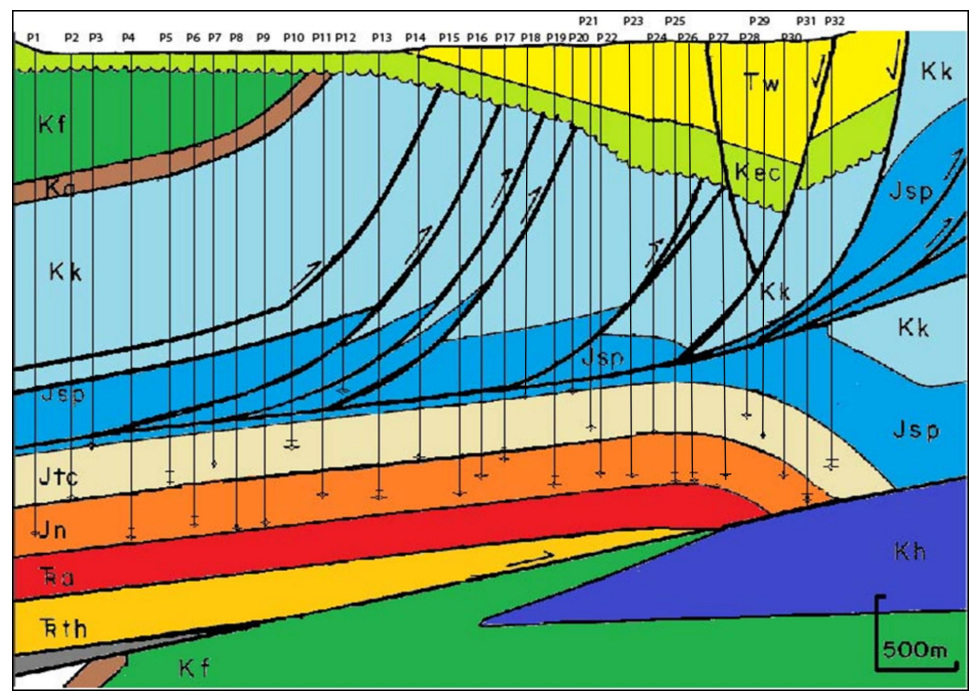

Figure $\mathbf{6}$ - Cross section of the Pineview Field with the location of the wells (P1 to P32), adapted from Deming \& Chapman (1988).

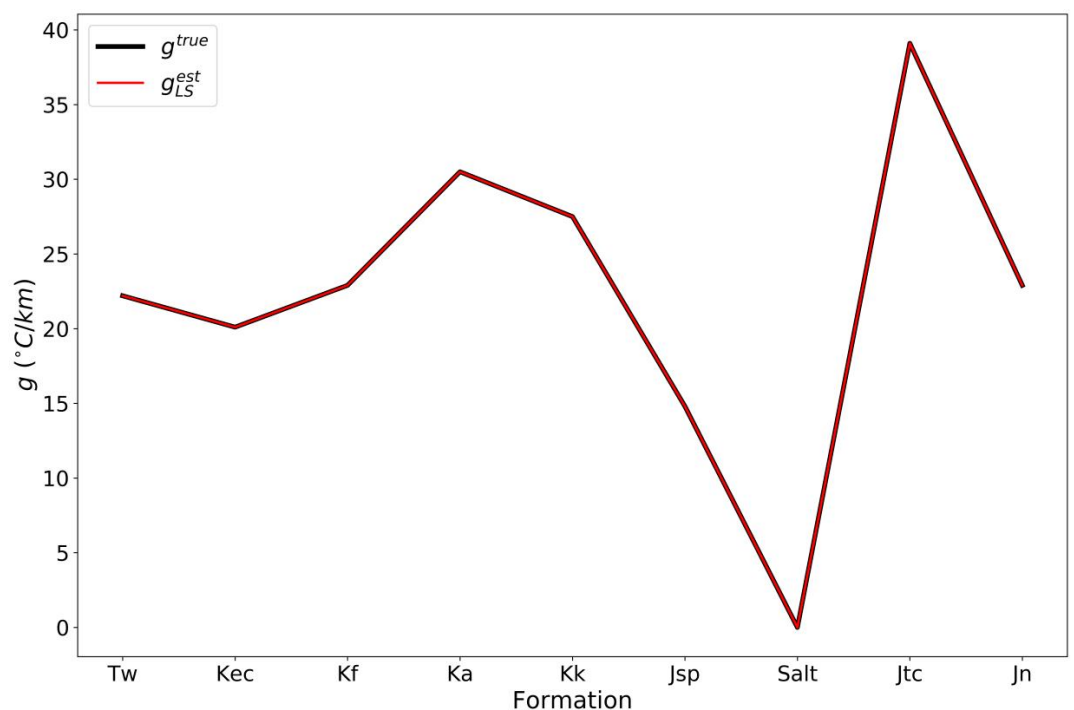

Figure 7 - True (black curve) and estimated (red curve) geothermal parameters. The estimated parameters were obtained by noise-free data inversion using least squares by SVD with all nine singular values. The coincidence between the two curves is due to the well-posedness of the inverse problem.

$\alpha=0.035, \alpha=0.07$ and $\alpha=0.1$. As mentioned before, the $\mathrm{L}$-curve is parametric, and the parameter is precisely the damping parameter $\varepsilon^{2}$, i.e., each point on the curve is associated with a specific value of $\varepsilon^{2}$. The four initial points are close, and the knee of the L-curve corresponds to the next value, that is, $\varepsilon^{2}=10^{4}$.
Note that this is exactly the value of $\varepsilon^{2}$ that generates the solution with the minimum value of $e_{R M S . g}$, as shown in Figure 8 .

Figure 11 compares the true model (black curve) with the estimated values of the geothermal gradient, when the temperature differences were contaminated with noise of factor 


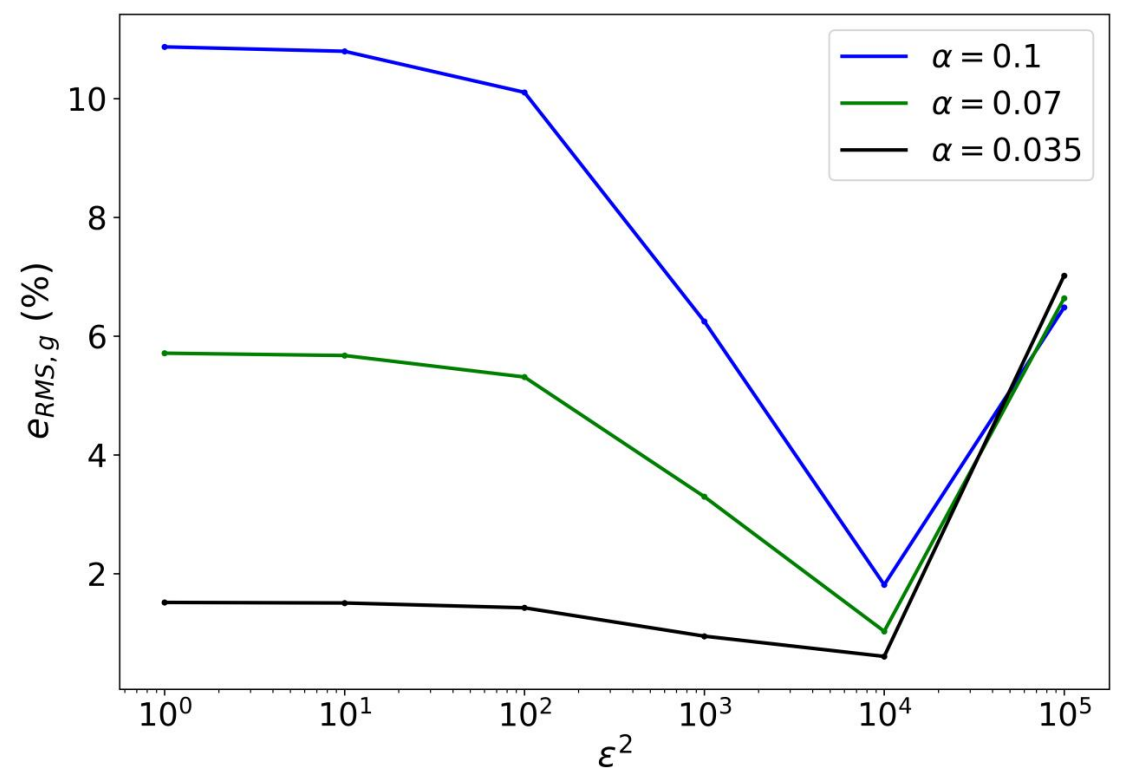

Figure 8 - Relative RMS model error between true geothermal gradients $g^{\text {true }}$ and estimated geothermal gradients $g^{\text {est }}$, obtained by damped least squares as a function of the damping parameter $\varepsilon^{2}$ for different noise levels given by the factor $\alpha$. Six values of $\varepsilon^{2}$ were tested, from $10^{0}$ to $10^{5}$. For all noise levels the minimum RMS error is associated with the optimum $\varepsilon^{2}=10^{4}$.

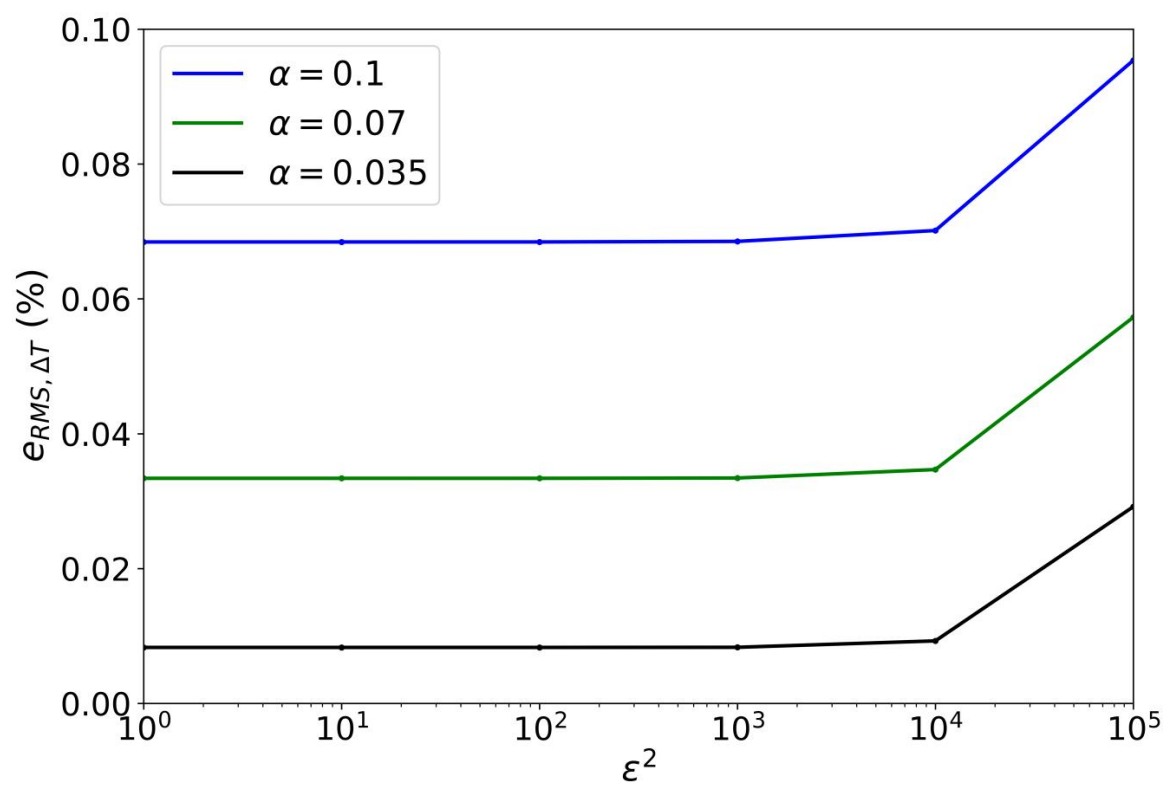

Figure 9 - Relative RMS data error between observed temperatures $\Delta T^{\text {obs }}$ and calculated temperatures $\Delta T^{c a l}$, as a function of the damping parameter $\varepsilon^{2}$ for different noise levels given by the factor $\alpha$. Six values of $\varepsilon^{2}$ were tested, from $10^{0}$ to $10^{5}$. For all noise levels, four values of $\varepsilon^{2}$ are associated with minimum RMS data error $\left(10^{0}\right.$ to $\left.10^{3}\right)$. The best solution, $\varepsilon^{2}=10^{4}$, defined from Figure 8 , does not have the minimum RMS data error. 


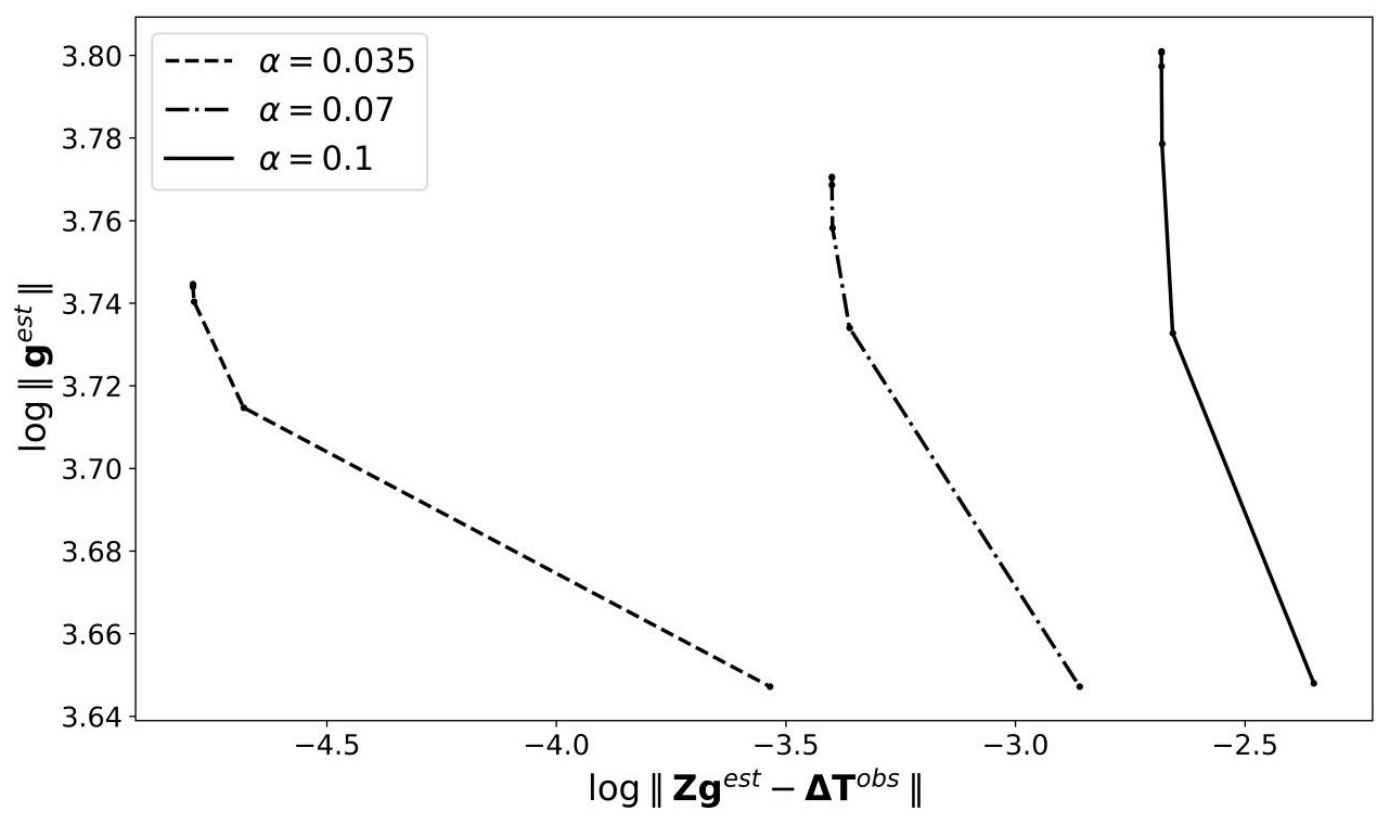

Figure 10 - Parametric L-curve for the selection of the optimum damping parameter $\varepsilon^{2}$. The observed temperatures $\Delta T^{\text {obs }}$ were corrupted by noise given by the factors $\alpha=0.035, \alpha=0.07$ and $\alpha=0.1$. The corner of the L-curve provides the trade-off between the amount of regularization (y axis) and data error (x axis); in all three cases, the optimum is $\varepsilon^{2}=10^{4}$.

$\alpha=0.035$. The least squares solution is represented by the red curve and the damped least squares method (blue curve) was obtained using the damping parameter $\varepsilon^{2}=10$ from the L-curve (Fig. 10). Note that the blue curve is closest to the true model. The deviation is more significant for Salt formation, which has two problems. First, the thickness of $45 \mathrm{~m}$ is small, compared to the other layers. It is true that the other formations are not present in all wells. However, when they are present, their thicknesses are a few hundred meters, in average. Second, salt has a high heat flow (for a given geothermal gradient) but a low geothermal gradient (for a given heat flow). Compare to other formations, the salt's geothermal gradient is small. These two aspects resulted in a higher sensibility to noise when estimating the geothermal gradient from BHT data.

As a matter of fact, the salt layer has two problems.

The RMS error $e_{R M S, g}$ between the true model and the estimated least squares method is $1.52 \%$, whereas the deviation between the true model and the model estimated by the damped least squares is $0.61 \%$, considerably smaller. The behavior is similar to other noise levels. Figure 12 shows the results with the noise factor $\alpha=0.07$, with a deviation being $5.72 \%$ between the true model and the least squares solution, which reduces to $1.03 \%$ between the true model and the damped least squares solution. Finally, Figure 13 presents the results for $\alpha=0.1$, with deviations of $10.88 \%$ and $1.82 \%$, respectively. In summary, the damped least squares method greatly improved the solution, i.e., the addition of $\varepsilon^{2}$ on the principal diagonal of $Z^{T} Z$ increased the matrix stability. This can be quantitatively explained by the fact that the matrix condition number, which is the ratio between the largest and the smallest singular value, decreased from 40160 in the least squares method to 5635 in the damped least squares method.

\section{CONCLUSIONS}

The objective of this study is to obtain the 1-D distribution of the geothermal gradient from the inversion of Bottom Hole Temperature (BHT) data. Before the inversion procedure, Horner correction method was used to determine the correct formation temperature. The inversions were performed in a synthetic model based on real data from Pineview Field (Utah, USA), in this case, to obtain geothermal gradients from nine formations using BHT data from 32 wells. The inversions using the least squares method did not produce good results, mainly for the determination of $g^{\text {est }}$ for Salt formation, because the inversion stability was affected by the low representativeness of this layer. The quality of the solutions improved significantly with damping, which was evidenced by the reduction of the RMS error between the true model and the estimated solution. Damping requires the choice 


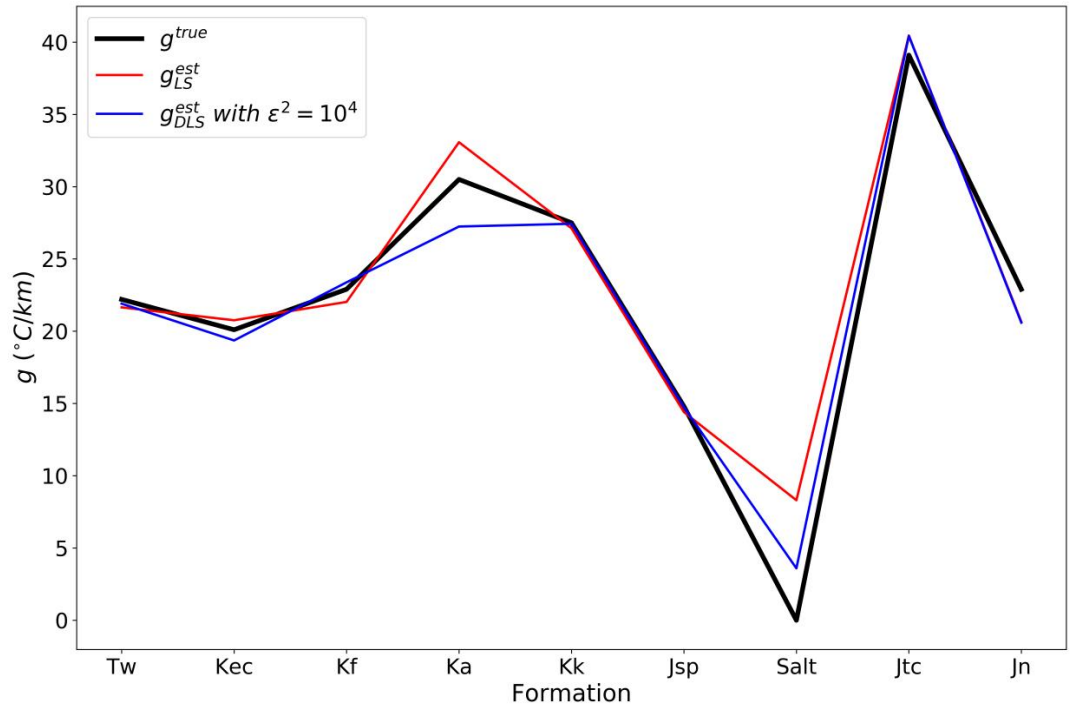

Figure 11 - Comparison between the true geothermal gradients $g^{\text {true }}$ (black curve) and the estimated solutions by least squares (red curve) and damped least squares (blue curve). The observed temperatures $\Delta T^{\text {obs }}$ were corrupted by noise given by the factor $\alpha=0.035$. The optimum damping parameter is $\varepsilon^{2}=10^{4}$, provided by the $L$-curve presented in Figure 10.

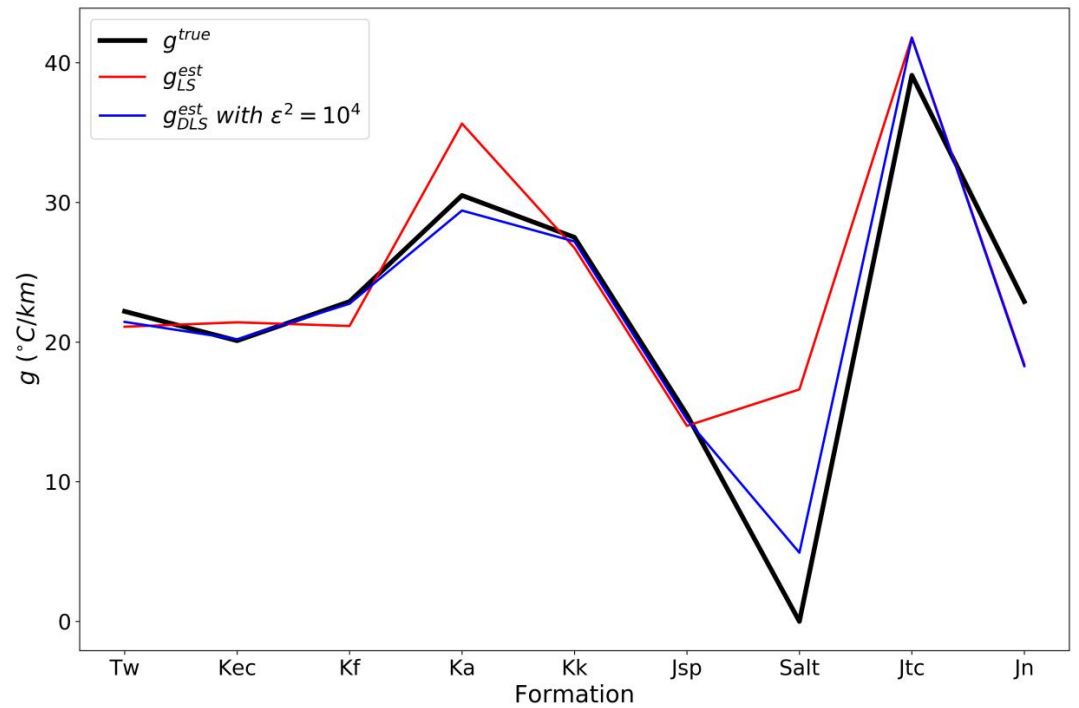

Figure 12 - Comparison between the true geothermal gradients $g^{\text {true }}$ (black curve) and the estimated solutions by least squares (red curve) and damped least squares (blue curve). The observed temperatures $\Delta T^{\text {obs }}$ were corrupted by noise given by the factor $\alpha=0.07$. The optimum damping parameter is $\varepsilon^{2}=10^{4}$, provided by the L-curve presented in Figure 10 . 


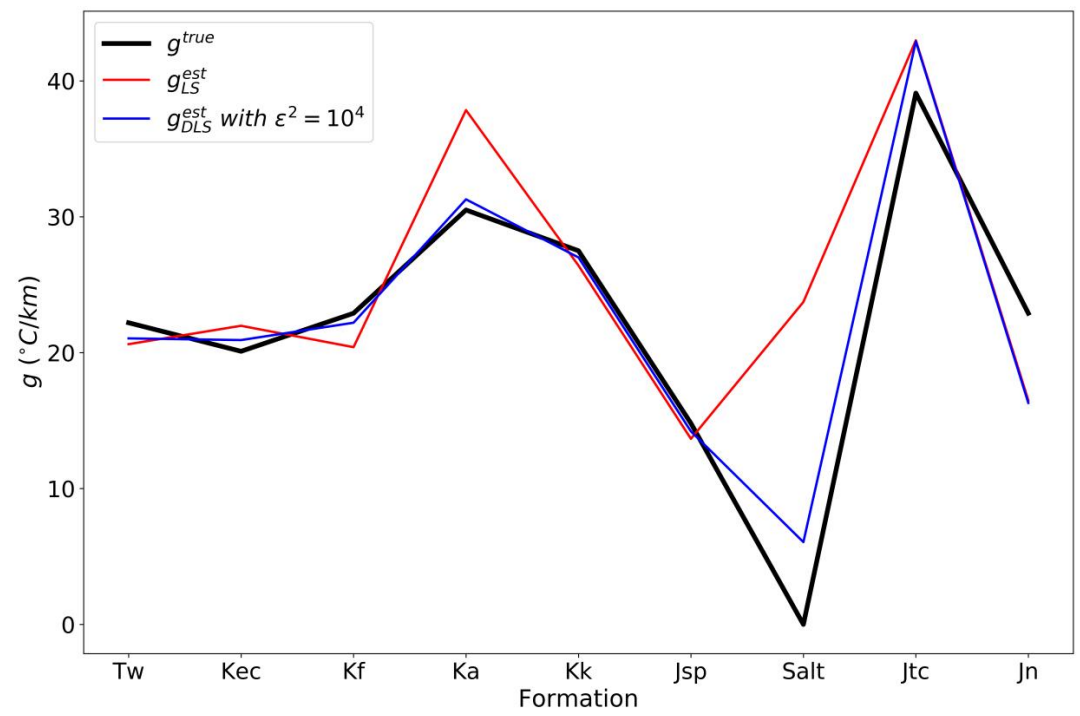

Figure 13 - Comparison between the true geothermal gradients $g^{\text {true }}$ (black curve) and the estimated solutions by least squares (red curve) and damped least squares (blue curve). The observed temperatures $\Delta T^{\text {obs }}$ were corrupted by noise given by the factor $\alpha=0.1$. The optimum damping parameter is $\varepsilon^{2}=10^{4}$, provided by the L-curve presented in Figure 10 .

of an optimal parameter, which was obtained from the L-curve. This can be quantitatively explained by the fact that the matrix condition number, which is the ratio between the largest and the smallest singular value, decreased from 40160 in the least squares method to 5635 in the damped least squares method. The results using the damped least squares method were in accordance to those obtained by Deming \& Chapman (1988).

\section{ACKNOWLEDGMENTS}

The authors thank FINEP for the project Rede Cooperativa de Pesquisa em Geofísica de Exploração, and CNPq for the project Instituto Nacional de Ciência e Tecnologia de Geofísica do Petróleo. This study was financed in part by the Coordenação de Aperfeiçoamento de Pessoal de Nível Superior - Brazil (CAPES) - Finance Code 001. The authors also thank FAPESB for project PIE00005/2016 (Edital de Infraestrutura FAPESB 003/2015).

\section{REFERENCES}

BULLARD EC. 1947. The time necessary for a bore hole to attain temperature equilibrium. Monthly Notices Royal Astronomical Society, Geophysical Supplement, 5(5): 127-130.

CARD0SO RA. 2007. Evolução Termo-Tectônica da Plataforma Continental do Estado do Rio de Janeiro. Master Dissertation, Observatório Nacional, Rio de Janeiro, Brazil. 162 pp.
CAVALCANTE AG. 2004. Correções de Dados de Temperatura de Fundo de Poço (BHT). Trabalho de Graduação, Universidade Federal da Bahia, Salvador, BA, Brazil. 75 pp.

CHAPMAN DS, KEHO TH, BAUER MS \& PICARD MD. 1984. Heat flow in the Uinta Basin determined from bottom hole temperature (BHT) data. Geophysics, 49: 453-466.

CHIDSEY TC Jr \& SPRINKEL DA. 2005. Major Oil Plays in Utah and Vicinity. Utah Geological Survey. Salt Lake City.

DEMING D \& CHAPMAN SD. 1988. Inversion of bottom-hole temperature data: the Pineview field, Utah-Wyoming thrust belt. Geophysics, 53: 707-720.

ELDORADO COUNTY WEATHER. 2018. Available on: $<$ http://www.eldoradocountyweather.com>. Access on: August 4, 2018.

FONTES LCAA. 1980. Determinação do Fluxo Geotérmico na Bacia Sedimentar Sergipe - Alagoas. Master Dissertation on Geophysics, Universidade Federal da Bahia, Salvador, BA, Brazil. 83 pp.

FOWLER CMR. 2005. The Solid Earth: An Introduction to Global Geophysics. 2nd ed., Cambridge University Press, Cambridge, UK. $685 \mathrm{pp}$.

HANSEN PC. 1992. Analysis of discrete III-posed problems by means of the L-curve. Society for Industrial and Applied Mathematics, SIAM Review, 34(4): 561-580. 
LACHENBRUCH AH \& BREWER MC. 1959. Dissipation of the temperature effect of drilling a well in Arctic Alaska. United States Geological Survey Bulletin, 1083-C: 73-109.

LANCZOS C. 1961. Linear Differential Operators. Van Nostrand, London. $580 \mathrm{pp}$.

LEVENBERG K. 1944. A method for the solution of the certain non-linear problems in least squares. Quartely of Applied Mathematics, 2: 164-168.

LUHESHI MN. 1983. Estimation of formation temperature from borehole measurements. Geophysical Journal of the Royal Astronomical Society, 74: 747-776.

MARQUARDT DW. 1963. An Algorithm for least-squares of nonlinear parameters. Journal of the Society for Industrial and Applied Mathematics, 11: 431-441.
MOJICA OF \& BASSREI A. 2015. Regularization parameter selection in the $3 \mathrm{D}$ gravity inversion of the basement relief using GCV: a parallel approach. Computers \& Geosciences, 82, 205-213.

PENROSE R. 1955. A generalized inverse for matrices. Proceedings of the Mathematical Society of Cambridge, 51: 406-413.

RODRIGUES VHSR \& BASSREI A. 2016. Seismic traveltime tomography applied to data from Miranga Field, Recôncavo Basin, Brazil. Revista Brasileira de Geofísica, 34(3): 351-362.

SILVA CJMG \& BASSREI A. 2016. Singular value selection and generalized cross validation in multi-frequency seismic diffraction tomography for $\mathrm{CO}_{2}$ injection monitoring. Revista Brasileira de Geofísica, 34(2): 175-192.

WAHBA G. 1990. Spline Models for Observational Data. In: CBMS-NSF Regional Conference Series in Applied Mathematics. v. 59, SIAM, Philadelphia. 169 pp.

Recebido em 27 de setembro de 2018 / Aceito em 15 de novembro de 2019

Received on September 27, 2018 / Accepted on November 15, 2019 